\begin{tabular}{|c|l|}
\hline Title & A nalysis of the degree of constant volume and cooling loss in a spark ignition engine fuel led with hydrogen \\
\hline Author(s) & Shudo, T.; Nabetani, S.; Nakajima, Y. \\
\hline Citation & $\begin{array}{l}\text { International Journal of Engine Research, 2(1), 81-92 } \\
\text { https://doi.org/10.1243/1468087011545361 }\end{array}$ \\
\hline Issue Date & 2001 \\
\hline Doc URL & http://hdl.handle.net/2115/32512 \\
\hline Type & article \\
\hline File Information & JER2-1(Heat2).pdf \\
\hline
\end{tabular}

Instructions for use 


\section{Analysis of the degree of constant volume and cooling loss in a spark ignition engine fuelled with hydrogen}

\author{
T Shudo \\ Department of Energy Science and Engineering, \\ Musashi Institute of Technology, Tokyo, Japan
}

\section{S Nabetani}

ZEXEL VALLEO Climate Control Corporation, Saitama, Japan

\section{Y Nakajima}

Department of Energy Science and Engineering, Musashi Institute of Technology, Tokyo, Japan

Received 28 November 2000

Abstract: This study analyses factors influencing the thermal efficiency of a homogeneous charge spark ignition (SI) engine fuelled with hydrogen, focusing on the degree of constant volume and the cooling loss. The cooling loss from the burning gas to the cylinder walls in a homogeneous charge SI engine is quantitatively evaluated by analysing the cylinder pressure diagram and the exhaust gas composition. The degree of constant volume burning and the degree of constant volume cooling are also obtained by fitting the Wiebe function to the rate of heat release calculated using the cylinder pressure diagram. A comparison of combustion and cooling characteristics between hydrogen and methane combustion reveals that the cooling loss in hydrogen combustion is higher than that of methane combustion due to a thinner quenching distance and faster burning velocity for hydrogen combustion. It is also made clear that the higher cooling loss in hydrogen combustion results in lower thermal efficiency of hydrogen combustion as compared to that of methane combustion.

Key words: thermal efficiency, SI engine, hydrogen, constant volume, cooling loss, combustion

\section{Introduction}

Hydrogen has been investigated as an alternative fuel for internal combustion engines since the 1920s
[1]. However, homogeneous charge hydrogenfuelled internal combustion engines sometimes suffer from the flash-back phenomenon during the intake stroke, especially in higher load operations. There have been reports on the mechanism or countermeasures for the flash-back phenomenon in hydrogen combustion $[2,3]$. The water injection into the intake manifold is an effective way to avoid the flash-back and to expand a range of operations in hydrogen combustion [3]. Although there has been a large amount of work done on the countermeasures for the flash-back and the expansion of the range of smooth operations, there do not seem to be any reports of a detailed analysis of thermal efficiency in hydrogen-fuelled internal combustion engines.

Hydrogen has unique characteristics in combustion which influence the thermal efficiency of internal combustion engines. For instance, hydrogen has a higher flame propagation velocity, a shorter quenching distance and a higher thermal conductivity compared with hydrocarbon fuels [4]. These characteristics of hydrogen supposedly have a strong influence on cooling loss and the degree of constant volume, both of which are major factors influencing the thermal efficiency of internal combustion engines. Measurements of the instantaneous heat flux on the combustion chamber wall in gasoline and diesel engines have been made by many researchers 
for the analysis of cooling loss in the engine. However, not much research has been done on the cooling loss in hydrogen-fuelled engines and nor do there seem to be any reports on the cooling loss ratio or other factors influencing thermal efficiency, such as the degree of constant volume.

In this study, the degree of constant volume burning and the degree of constant volume cooling in hydrogen combustion are analysed using the real rate of heat release obtained from the pressure diagram and the exhaust gas composition. The instantaneous heat flux on the combustion chamber wall is also measured using a thermocouple. The effect of these measured parameters on thermal efficiency of an engine fuelled with hydrogen will be discussed in detail.

\section{Experimental Apparatus and Procedure}

The test engine used was a four-stroke four-cylinder spark ignition gas engine which was modified from a gasoline engine for passenger cars (bore $85 \mathrm{~mm}$, stroke $88 \mathrm{~mm}$, compression ratio 8.5). Hydrogen or methane was continuously supplied to the intake manifold. The fuel gas flowrate was measured with a mass flowmeter (Oval, F203S). In all of the experiments conducted, the engine speed was set at $1500 \mathrm{r} / \mathrm{min}$ and the volumetric efficiency was set at $\eta_{\mathrm{v}}=50$ per cent including fuel gas in order to avoid the flash-back phenomenon. The in-cylinder pressure was measured with a piezoelectric-type pressure transducer (AVL, GM12D) installed on the cylinder head as shown in Fig. 1. The pressure data were averaged over 200 cycles and used to calculate the indi-

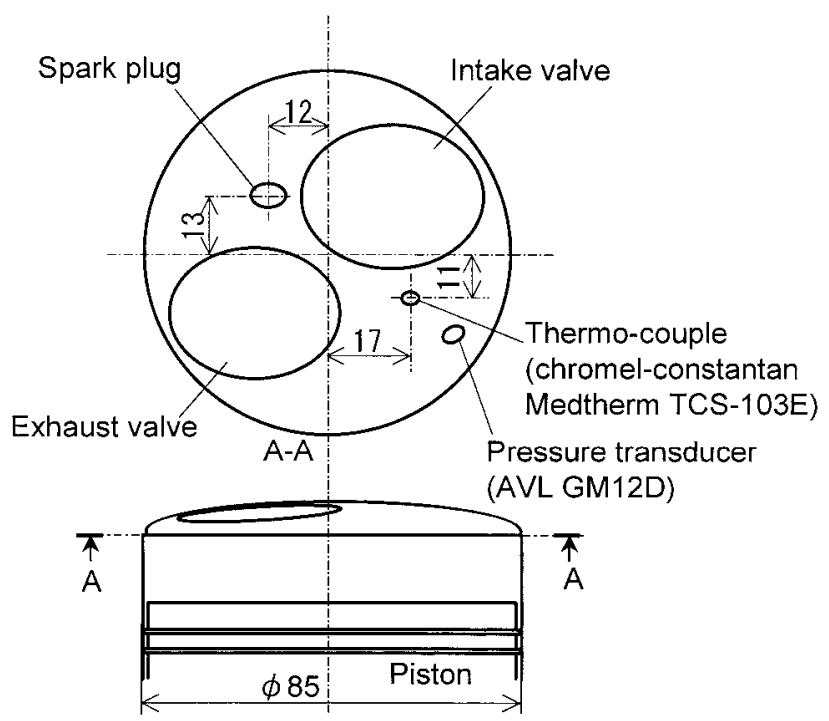

Fig. 1 Combustion chamber geometry of the tested engine. cated thermal efficiency, the rate of heat release, the degree of constant volume, etc. The instantaneous temperature was measured using a thin-film-type thermocouple (Medtherm, TCS-103E, chromelconstantan type) at a location on the cylinder head as shown in Fig. 1. The exhaust gas was analysed using an exhaust gas analyser (Horiba, MEXA 9100) for calculation of the combustion efficiency.

\section{Results and Discussion}

\subsection{Calculation of the cooling loss ratio using an indicator diagram}

The cylinder pressure and instantaneous wall temperature were measured varying the ignition timing for both hydrogen and methane combustion. A comparison of measured and calculated values of the cylinder pressure between hydrogen and methane combustion is presented in Fig. 2. The ordinates in the figure give the in-cylinder pressure, the apparent rate of heat release $\mathrm{d} Q / \mathrm{d} \theta$, the cumulative apparent heat release $Q$, the in-cylinder gas temperature and the instantaneous temperature of the combustion chamber wall against the crank angle. The excess air ratio was set at $\lambda=1.0$, stoichiometric. The apparent rate of heat release $\mathrm{d} Q / \mathrm{d} \theta$ was calculated as follows:

$$
\frac{\mathrm{d} Q}{\mathrm{~d} \theta}=\frac{V \mathrm{~d} P / \mathrm{d} \theta+\gamma P \mathrm{~d} V / \mathrm{d} \theta}{\gamma-1}-P \frac{V}{(\gamma-1)^{2}} \frac{\mathrm{d} \gamma}{\mathrm{d} \theta}
$$

The ratio of specific heats $\gamma$ was calculated with the composition and mean temperature of the in-cylinder gas and treated as a variable. Though the term of $\mathrm{d} \gamma / \mathrm{d} \theta$ is relatively small in hydrocarbon combustion and is sometimes neglected, hydrogen combustion has a larger $\mathrm{d} \gamma / \mathrm{d} \theta$ due to rapid change in the composition and temperature of the in-cylinder gas. The contribution of the second term on the right side of equation (1), $P V /(\gamma-1)^{2} \mathrm{~d} \gamma / \mathrm{d} \theta$, to the apparent rate of heat release $\mathrm{d} Q / \mathrm{d} \theta$ is as high as 30 per cent in the stoichiometric combustion of hydrogen.

The figure shows that hydrogen combustion has a shorter combustion period due to a higher burning velocity than methane. In both fuels, the combustion chamber wall temperature tends to increase with an advance in ignition timing. Hydrogen combustion has a larger temperature swing during the combustion period. It is interesting to note that the apparent rate of heat release $\mathrm{d} Q / \mathrm{d} \theta$ in hydrogen combustion is influenced significantly by the cooling loss. The negative rate of heat release observed after the end of combustion suggests that hydrogen combustion 


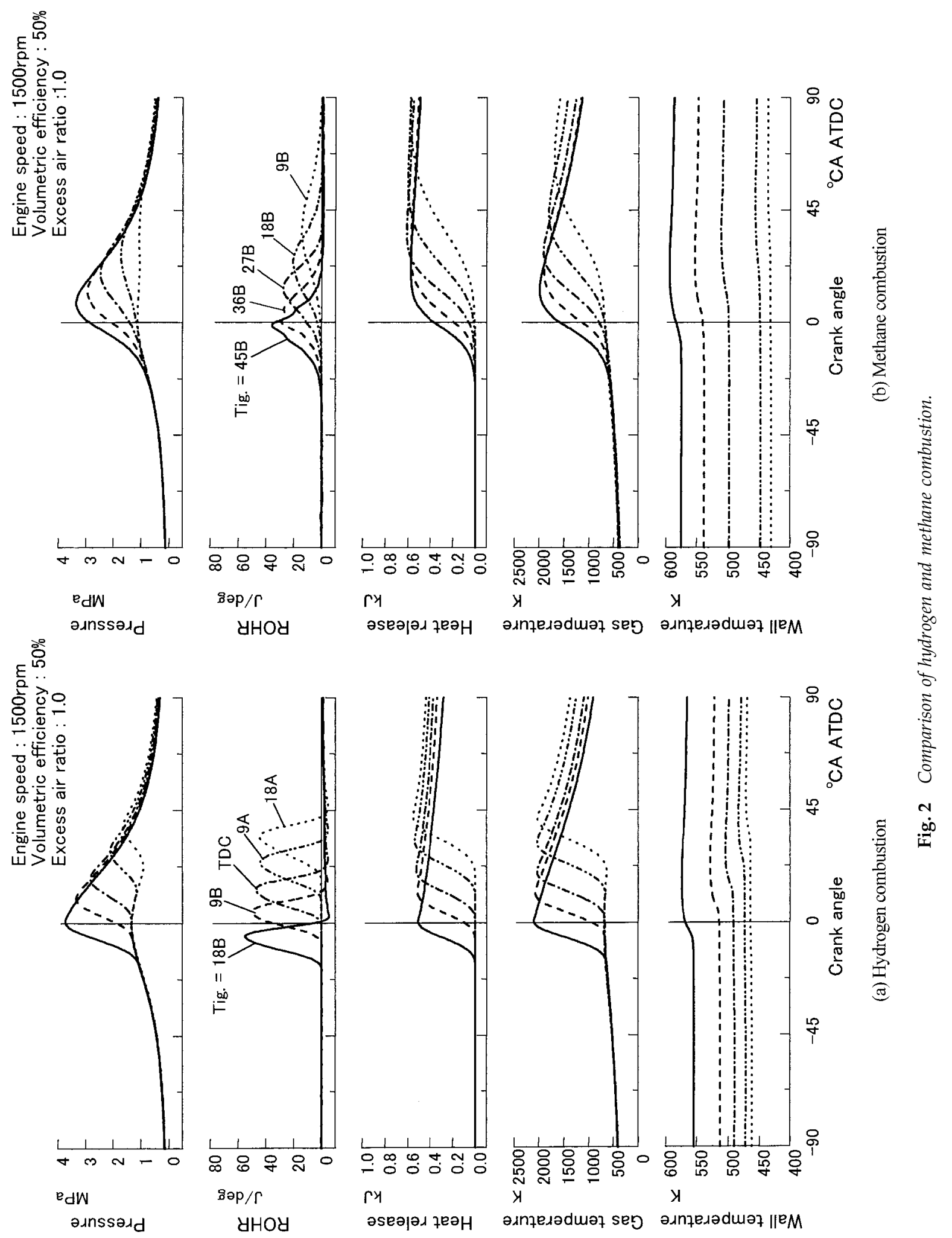


has a higher cooling loss compared with methane combustion. The higher cooling loss for hydrogen combustion could be attributed to a thin temperature boundary layer thickness on the combustion chamber wall due to a shorter quenching distance [4]. The high burning velocity for hydrogen combustion may also cause intense convection between the burning gas and the wall, resulting in an enhancement of the heat transfer.

By considering the effect of cooling loss on the rate of heat release, factors influencing the thermal efficiency of the hydrogen engine will be discussed. Indicated thermal efficiency $\eta_{\mathrm{i}}$ of a spark ignition (SI) engine is expressed by [5]

$$
\eta_{\mathrm{i}}=\eta_{\mathrm{th}} \eta_{\mathrm{glh}} \eta_{\mathrm{u}}\left(1-\phi_{\mathrm{w}}\right)
$$

where $\eta_{\text {th }}$ is the theoretical thermal efficiency of Otto cycle, $\eta_{\text {glh }}$ is the degree of constant volume, $\eta_{\mathrm{u}}$ is the combustion efficiency and $\phi_{\mathrm{w}}$ is the cooling loss ratio. The degree of constant volume $\eta_{\text {glh }}$ was calculated by the following equation from the apparent rate of heat release $\mathrm{d} Q / \mathrm{d} \theta$ :

$$
\eta_{\mathrm{glh}}=\frac{1}{\eta_{\mathrm{th}} Q} \int\left\{1-\left[\frac{V_{\mathrm{h}}+V_{\mathrm{c}}}{V(\theta)}\right]^{1-\gamma}\right\} \frac{\mathrm{d} Q}{\mathrm{~d} \theta} \mathrm{d} \theta
$$

To express quantitatively the fraction of the cooling heat loss in the real heat release, an index, $\eta_{\mathrm{u}}\left(1-\phi_{\mathrm{w}}\right)$ or $Q / Q_{\text {fuel }}$, is introduced. The cumulative apparent heat release $Q$ can be related to the cumulative real heat release $Q_{\mathrm{B}}$ and the cumulative cooling loss $Q_{\mathrm{C}}$ as follows:

$$
Q=Q_{\mathrm{B}}-Q_{\mathrm{C}}
$$

If the combustion efficiency is denoted as $\eta_{\mathrm{u}}, Q / Q_{\text {fuel }}$ can be written as

$$
\frac{Q}{Q_{\text {fuel }}}=\left(Q_{\mathrm{B}}-Q_{\mathrm{C}}\right) \frac{\eta_{\mathrm{u}}}{Q_{\mathrm{B}}}
$$

and $Q / Q_{\text {fuel }}$ can be rewritten using the cooling loss ratio $\phi_{\mathrm{w}}$ defined as $\phi_{\mathrm{w}}=Q_{\mathrm{C}} / Q_{\mathrm{B}}$ :

$$
\frac{Q}{Q_{\text {fuel }}}=\eta_{\mathrm{u}}\left(1-\phi_{\mathrm{w}}\right)
$$

If the combustion efficiency $\eta_{\mathrm{u}}$ is given by the exhaust gas analysis, the cooling loss ratio $\phi_{\mathrm{w}}$ can be quantified from the heat release analysis.

Figure 3 shows a comparison of the effects of ignition timing on the thermal efficiency and its components between hydrogen and methane combustion at the stoichiometric excess air ratio. It can be seen from the figure that the trend of the curve of $\eta_{\mathrm{glh}} \eta_{\mathrm{u}}\left(1-\phi_{\mathrm{w}}\right)$ is very similar to that of the indicated thermal efficiency $\eta_{\mathrm{i}}$. This correlation and equa-

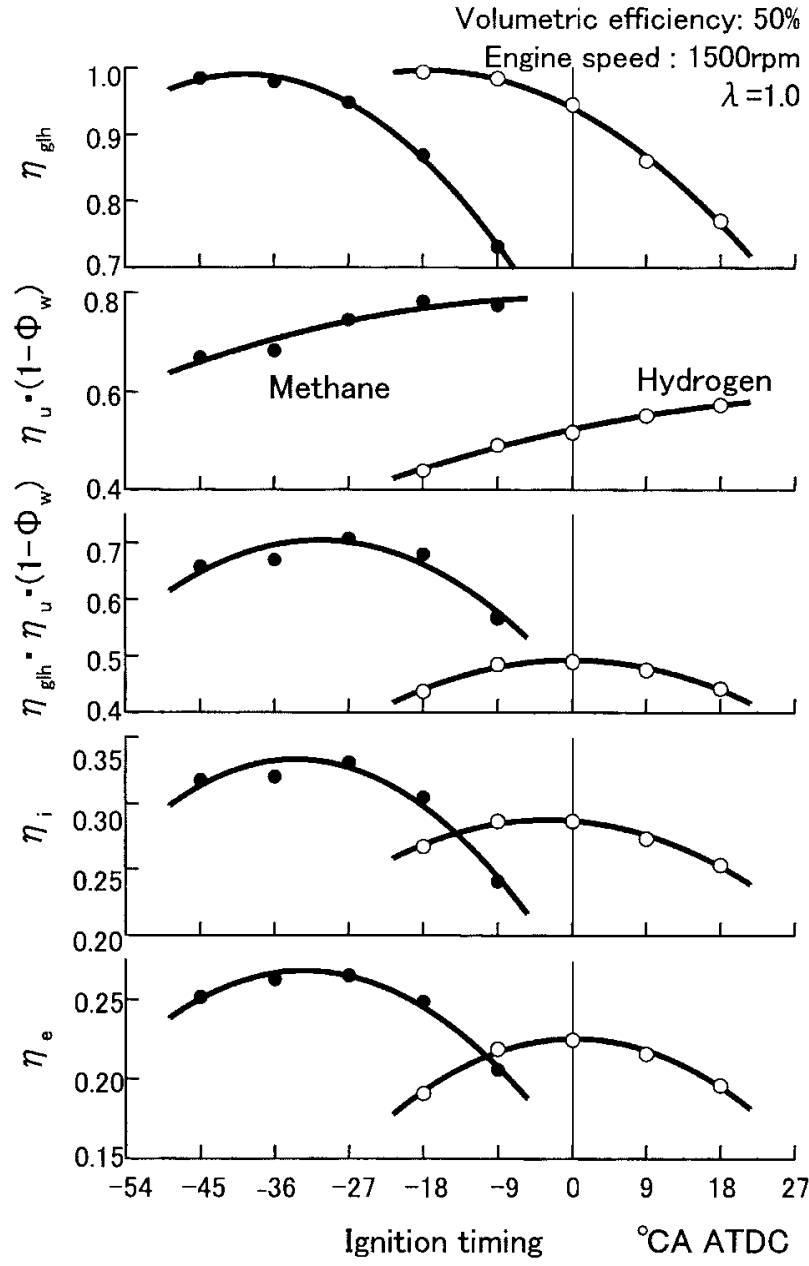

Fig. 3 Influence of ignition timing on components of thermal efficiency.

tion (2) suggest that the theoretical thermal efficiency $\eta_{\text {th }}$ remains almost constant at various ignition timings. Accordingly, the degree of constant volume $\eta_{\mathrm{glh}}$ and $\eta_{\mathrm{u}}\left(1-\phi_{\mathrm{w}}\right)$ are the two dominant factors used to determine the thermal efficiency in SI engines. In hydrogen combustion, a higher degree of constant volume $\eta_{\mathrm{glh}}$ is achieved even with retarded ignition timings, but $\eta_{\mathrm{u}}\left(1-\phi_{\mathrm{w}}\right)$ is lower than in methane combustion. The lower $\eta_{\mathrm{u}}\left(1-\phi_{\mathrm{w}}\right)$ means a higher cooling loss because the combustion efficiency $\eta_{\mathrm{u}}$ in homogeneous charge stoichiometric combustion hardly changes with the changes in ignition timing [6]. The larger cooling loss for hydrogen combustion resulted in lower thermal efficiencies at throttled stoichiometric conditions.

Figure 4 shows the effect of ignition timing on the cooling loss ratio $\phi_{\mathrm{w}}$. In combustion of both fuels, the cooling loss ratio $\phi_{\mathrm{w}}$ tends to increase with an advance in ignition timing. It is worth noting that hydrogen combustion has a significantly higher cooling loss ratio $\phi_{\mathrm{w}}$ than methane combustion at the same ignition timing or the optimum ignition timing for thermal efficiency at MBT (minimum ignition 


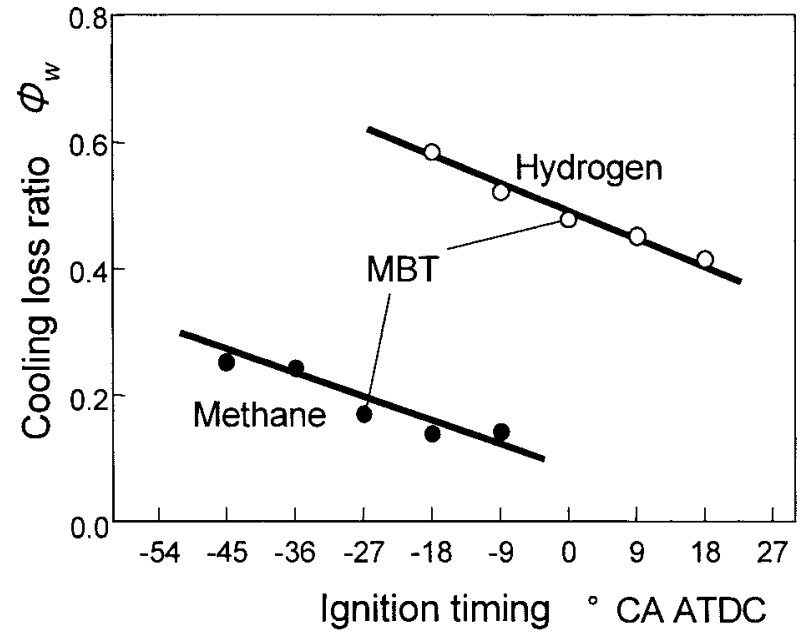

Fig. 4 Influence of ignition timing on the heat loss ratio.

advance for best torque). The result suggests that reduction of the cooling loss is essential to achieve higher thermal efficiency in hydrogen-fuelled engines.

Figure 5 shows the influence of ignition timing on instantaneous heat flux calculated from the time record of the surface temperature measured at a representative location in the cylinder head shown in Fig. 1. It is seen in the figure that advanced ignition timing causes the heat flux to increase for both fuels and that hydrogen combustion has a higher heat flux on the wall than methane combustion at all ignition timings. Figure 6 shows the maximum value of the instantaneous heat flux against the ignition timing. The instantaneous heat flux presented in this figure is a local information and does not correspond directly to the total cooling loss in the combustion chamber. However, the trends of heat flux against ignition timing for both fuels are very similar to those for the total cooling loss versus ignition timing shown in Fig. 4. This implies that the cooling loss analysis with the indicator diagram applied in this study is informative enough to see the trend of the cooling loss.

\subsection{Estimation of the real rate of heat release using the Wiebe function}

The degree of constant volume burning and the degree of constant volume cooling are two important indices in thermal efficiency analysis. The degree of constant volume cooling $\eta_{\mathrm{glC}}$ is especially important in the cycle analysis of a hydrogen-fuelled engine because of its high cooling loss fraction. The degree of constant volume burning and the degree of constant volume cooling can be calculated using the real rate of heat release $d Q_{B} / d \theta$ and the rate of cooling $\mathrm{d} Q_{\mathrm{C}} / \mathrm{d} \theta$. However, it is impossible to measure directly the real rate of heat release $d Q_{B} / d \theta$ and to obtain the rate of cooling $\mathrm{d} Q_{\mathrm{C}} / \mathrm{d} \theta$ from the measured instantaneous local heat flux. For this reason, a combustion function was employed in this study to approximate the real rate of heat release. From among various combustion functions describing the mass burnt fraction [7-9], the following Wiebe function [7] was chosen:

$$
x(\theta)=1-\exp \left[-A\left(\frac{\theta-\theta_{\mathrm{f}}}{\theta_{\mathrm{z}}}\right)^{m^{+}}\right]
$$

where $\theta_{\mathrm{f}}$ is the beginning of the combustion period and $\theta_{\mathrm{z}}$ is the combustion period. The coefficients $A$ and $m$ in the Wiebe function were adjusted so that the function could fit the curve of the cumulative apparent heat release $Q$ during the combustion period. The coefficients $m$ determined were 2.0 and 3.0 for hydrogen and methane combustion respectively for all of the ignition timings. Another coefficient $A$ in the function was varied in each case for the best fit. The curve fitted to the cumulative apparent heat release $Q$ was multiplied by $\eta_{\mathrm{u}} Q_{\text {fuel }} / Q$, i.e. $Q_{B} / Q$, to give the cumulative real heat release, based on the assumption that the real and apparent rates of heat release are analogous to each other. The rate of cooling $\mathrm{d} Q_{\mathrm{C}} / \mathrm{d} \theta$ was obtained from the real rate of heat release $d Q_{B} / d \theta$ and the apparent rate of heat release $\mathrm{d} Q / \mathrm{d} \theta$ :

$$
\frac{\mathrm{d} Q_{\mathrm{C}}}{\mathrm{d} \theta}=\frac{\mathrm{d} Q_{\mathrm{B}}}{\mathrm{d} \theta}-\frac{\mathrm{d} Q}{\mathrm{~d} \theta}
$$

The degree of constant volume burning $\eta_{\mathrm{glB}}$ and the degree of constant volume cooling $\eta_{\mathrm{glC}}$ are defined as follows:

$$
\begin{aligned}
& \eta_{\mathrm{glB}}=\frac{1}{\eta_{\mathrm{th}} Q_{\mathrm{B}}} \int\left\{1-\left[\frac{V_{\mathrm{h}}+V_{\mathrm{c}}}{V(\theta)}\right]^{1^{-\gamma}}\right\} \frac{\mathrm{d} Q_{\mathrm{B}}}{\mathrm{d} \theta} \mathrm{d} \theta \\
& \eta_{\mathrm{glC}}=\frac{1}{\eta_{\text {th }} Q_{\mathrm{C}}} \int\left\{1-\left[\frac{V_{\mathrm{h}}+V_{\mathrm{c}}}{V(\theta)}\right]^{1-\gamma}\right\} \frac{\mathrm{d} Q_{\mathrm{C}}}{\mathrm{d} \theta} \mathrm{d} \theta
\end{aligned}
$$

The degree of constant volume $\eta_{\mathrm{glh}}$ can be related to $\eta_{\mathrm{glB}}$ and $\eta_{\mathrm{glC}}$ :

$$
Q \eta_{\mathrm{glh}}=Q_{\mathrm{B}} \eta_{\mathrm{glB}}-Q_{\mathrm{C}} \eta_{\mathrm{glC}}
$$

From equations (2), (5) and (11), the indicted thermal efficiency $\eta_{\mathrm{i}}$ is described using the degree of constant volume burning $\eta_{\mathrm{glB}}$ and the degree of constant volume cooling $\eta_{\mathrm{glC}}$ as follows:

$$
\eta_{\mathrm{i}}=\eta_{\mathrm{th}} \eta_{\mathrm{u}}\left(\eta_{\mathrm{glB}}-\phi_{\mathrm{w}} \eta_{\mathrm{glC}}\right)
$$




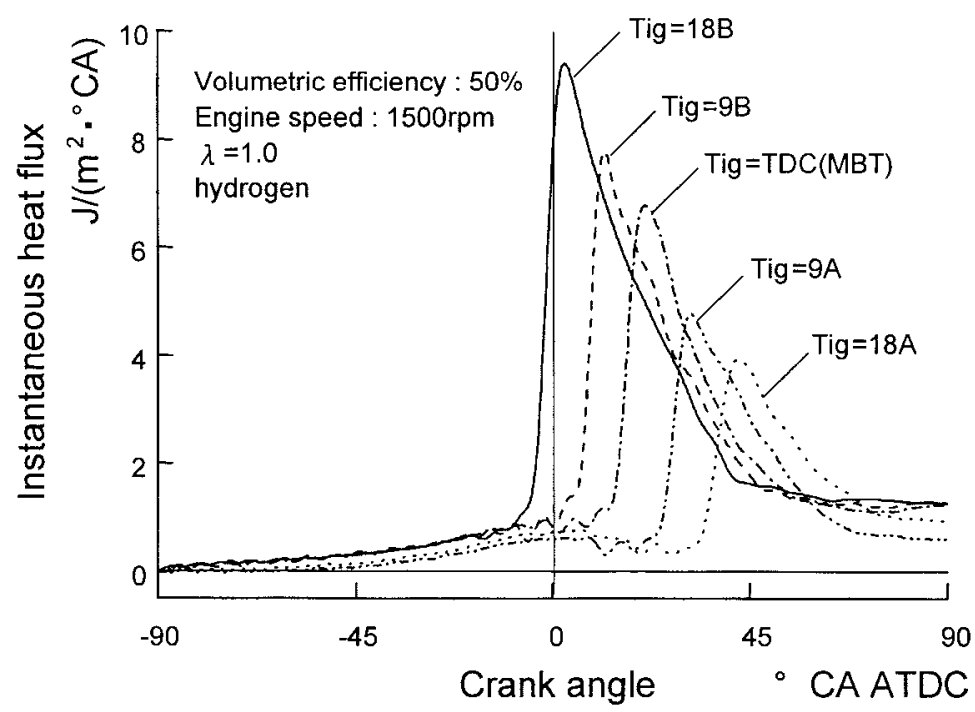

(a) Hydrogen combustion

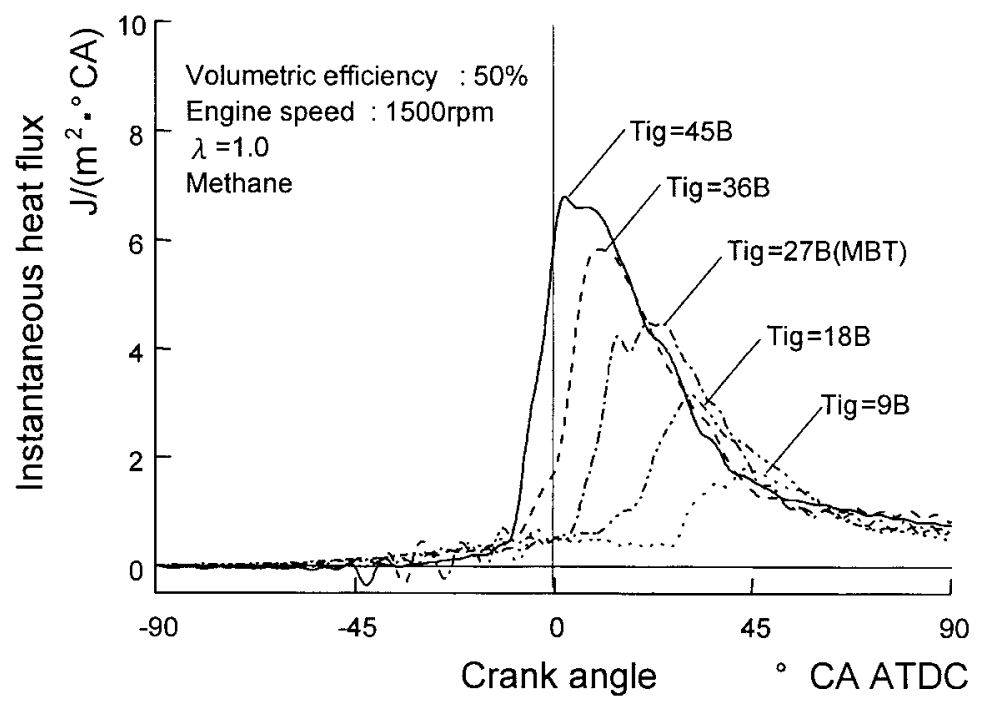

(b) Methane combustion

Fig. 5 Instantaneous heat flux for different ignition timings.

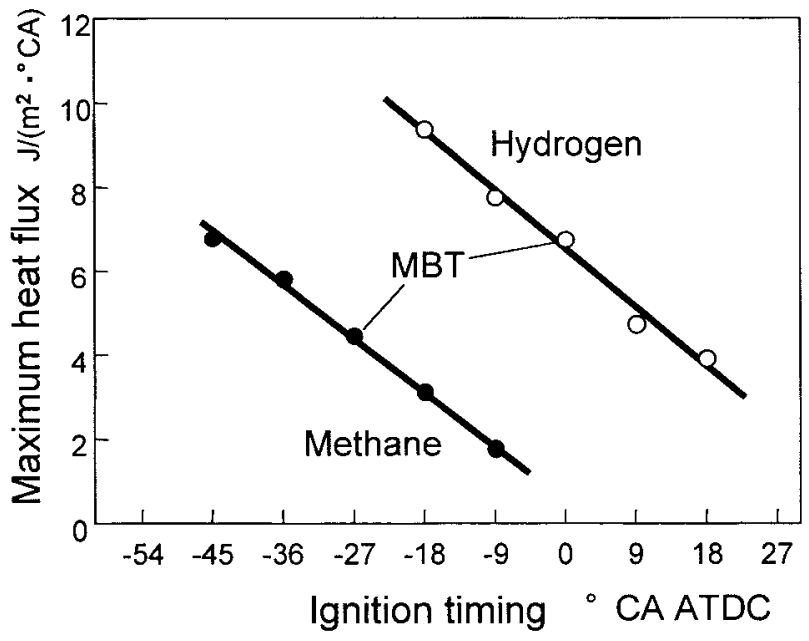

Fig. 6 Influence of ignition timing on the maximum heat flux.

\subsection{The degree of constant volume burning and the degree of constant volume cooling}

\subsubsection{Influence of ignition timing}

Figure 7 shows the influence of ignition timing on the in-cylinder pressure, the cumulative apparent heat release $Q$, the cumulative real heat release $Q_{\mathrm{B}}$ and the cumulative cooling loss $Q_{C}$. The cumulative real heat release $Q_{\mathrm{B}}$ and the cumulative cooling loss $Q_{C}$ were estimated using the Wiebe function, as described in the previous section. The cumulative cooling loss $Q_{\mathrm{w}}$ was calculated using the Woschni correlation [10] and was presented in the figure as a reference. As can be seen in a comparison between $Q_{C}$ and $Q_{w}$, the application of the Woschni correlation is apparently unsuccessful in describing the cooling loss in hydrogen and methane combustion. 

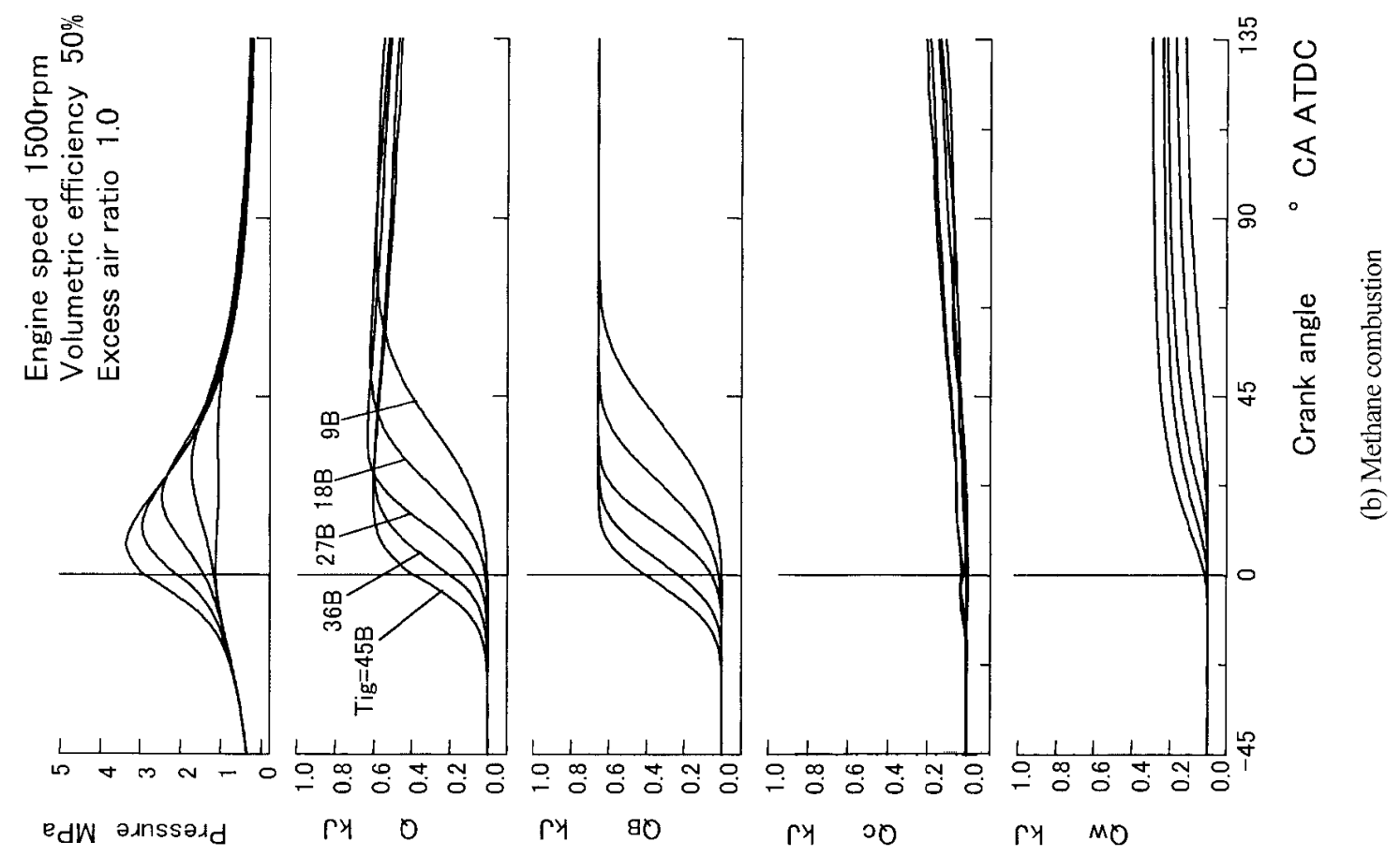

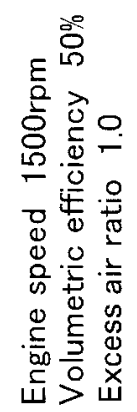

edW aגnssald

ry 0

ry 90

ry 00

ry MO

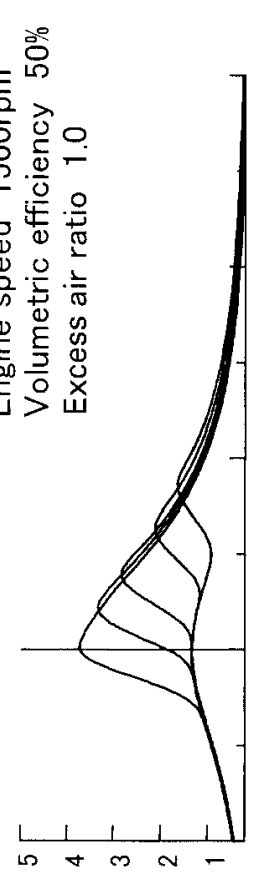

edW aגnssadd
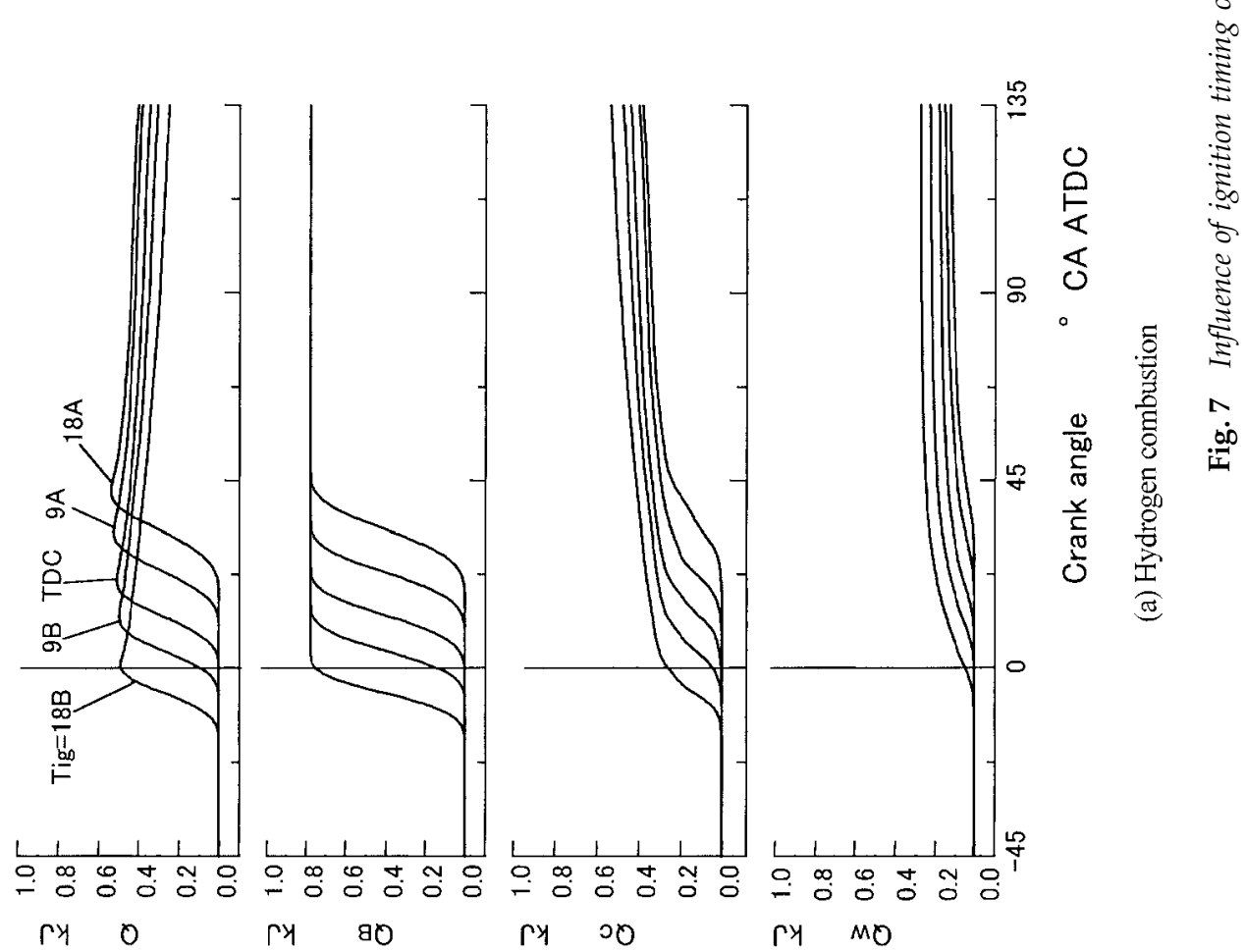
It should be noted in the figure that the cooling loss in hydrogen combustion is significantly higher than that in methane combustion. The higher cooling loss ratio in hydrogen combustion could be attributed to the thin temperature boundary layer thickness due to a short quenching distance. The high burning velocity of hydrogen combustion may have some positive effect on increasing heat transfer between the burning gas and the combustion chamber walls.

Figure 8 shows the variations of the degree of constant volume burning $\eta_{\mathrm{glB}}$ and the degree of constant volume cooling $\eta_{\mathrm{glC}}$ with the change in ignition timing of the fuel as a parameter. It can be seen in the figure that $\eta_{\mathrm{glB}}$ has the same level for both hydrogen and methane combustion, although the curve for hydrogen is shifted later against the ignition timing. It is also seen that regardless of the fuel both $\eta_{\mathrm{glB}}$ and $\eta_{\mathrm{glC}}$ increase with an advance in ignition timing. As expected, the degree of constant volume cooling $\eta_{\mathrm{glC}}$ in hydrogen combustion is very much higher than in methane combustion in a range of ignition timing tested. Hydrogen combustion at MBT exhibits a higher degree of constant volume cooling than methane combustion at MBT, although both fuels have a similar degree of constant volume burning.
3.3.2 Influence of the excess air ratio on thermal efficiency

The influence of the excess air ratio on indicated and brake thermal efficiencies, $\eta_{\mathrm{i}}$ and $\eta_{\mathrm{e}}$, as well as parameters affecting the thermal efficiencies, is shown in Fig. 9. Ignition timing was set at MBT for each fuel and excess air ratio. It can be seen that one of the features of hydrogen combustion is the wide range of operating conditions in regard to the excess air ratio. The degree of constant volume $\eta_{\text {glh }}$ for hydrogen combustion keeps a high level over a wide range of excess air ratios because of the wide flammable range and high burning velocity. Since $\eta_{\text {glh }}$ remains almost constant against the excess air ratio, the indicated thermal efficiency $\eta_{\mathrm{i}}$ is determined predominantly by $\eta_{\mathrm{u}}\left(1-\phi_{\mathrm{w}}\right)$, as indicated by equation (2). The result of heat flux measurements shown in Fig. 10 provides support for the trend in $\eta_{\mathrm{u}}\left(1-\phi_{\mathrm{w}}\right)$ versus the excess air ratio. However, hydrogen combustion at 50 per cent volumetric efficiency has lower $\eta_{\mathrm{u}}\left(1-\phi_{\mathrm{w}}\right)$ and lower thermal efficiency, even in leaner mixture conditions.

Figure 11 shows the cooling loss ratio $\phi_{\mathrm{w}}$, the degree of constant volume burning $\eta_{\mathrm{glB}}$ and the degree of constant volume cooling $\eta_{\mathrm{glc}}$. The behaviour of the cooling loss ratio $\phi_{\mathrm{w}}$ against the excess air ratio is similar to the tendency of the maximum value of the instantaneous heat flux against the
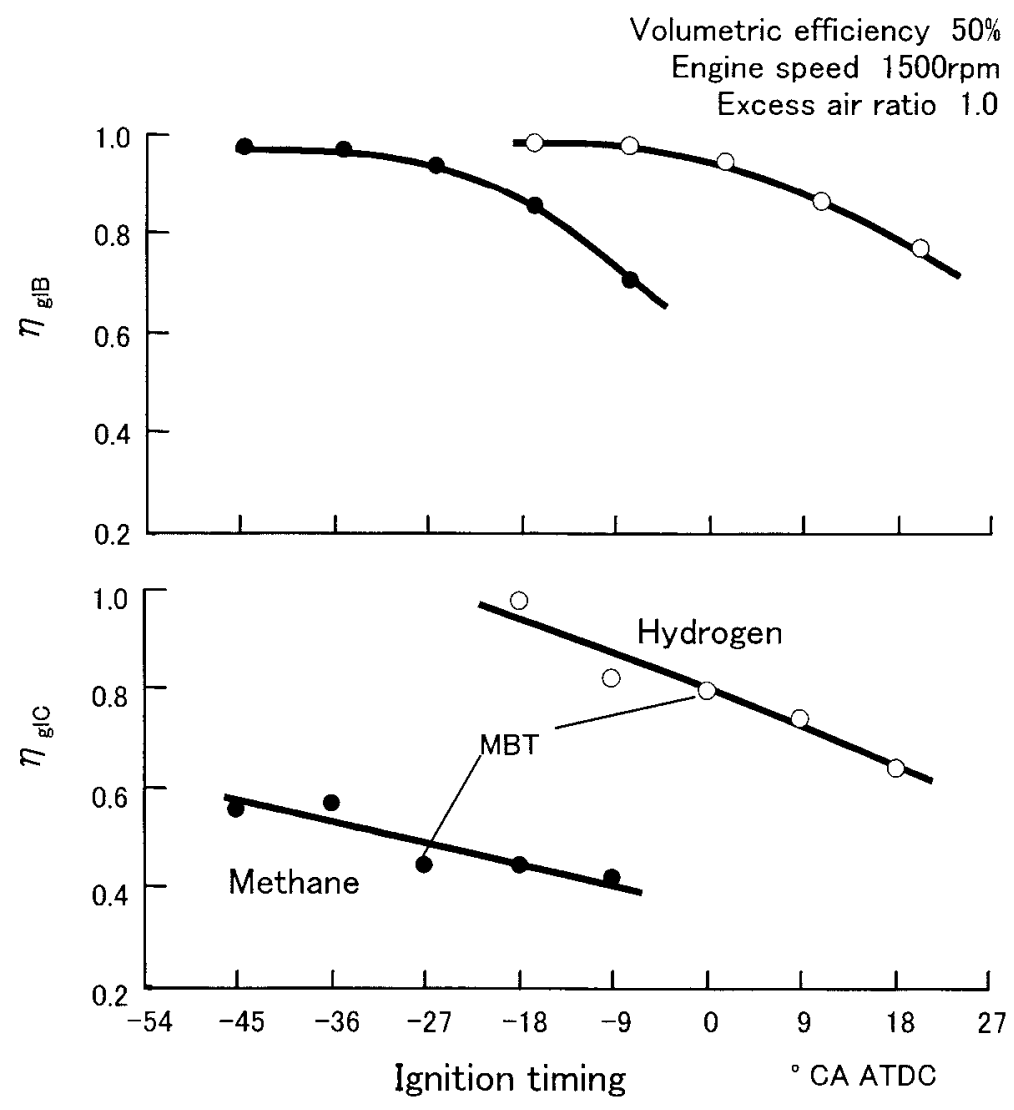

Fig. 8 Influence of ignition timing on $\eta_{\mathrm{glB}}$ and $\eta_{\mathrm{glC}}$. 


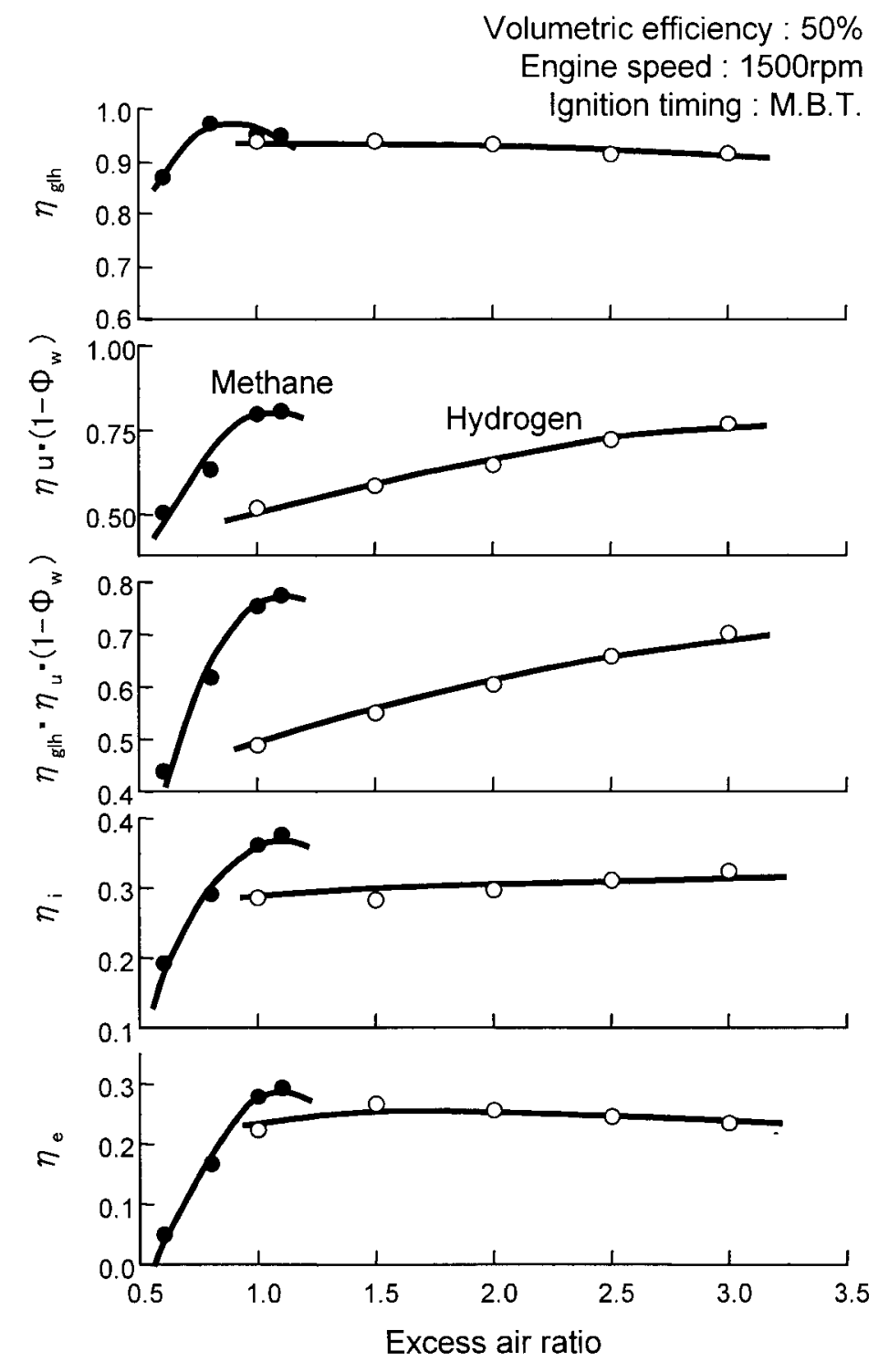

Fig. 9 Influence of the excess air ratio on components of thermal efficiency.

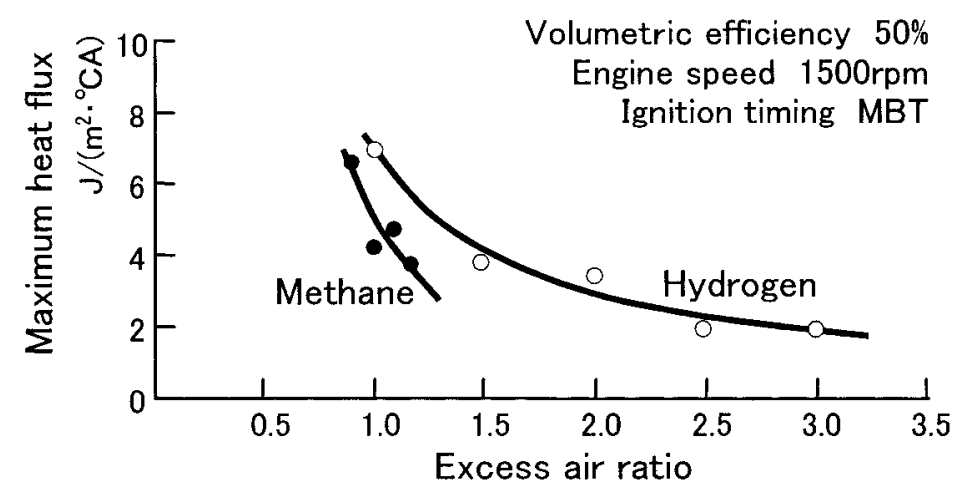

Fig. 10 Influence of the excess air ratio on the maximum instantaneous heat flux.

excess ratio shown in Fig. 10. Although hydrogen combustion has a higher degree of constant volume burning $\eta_{\mathrm{glB}}$, even under fuel lean mixture conditions, the degree of constant volume cooling $\eta_{\text {glC }}$ and cooling loss ratio $\phi_{\mathrm{w}}$ are also higher than in methane combustion. The advantage of a high constant volume burning is cancelled by the disadvan- tage of the high cooling loss in hydrogen combustion. This trend yields lower thermal efficiencies to hydrogen-fuelled engines.

\subsection{Exhaust heat analysis with indicator diagram}

The high cooling loss ratio and the high degree of constant volume of hydrogen combustion are 


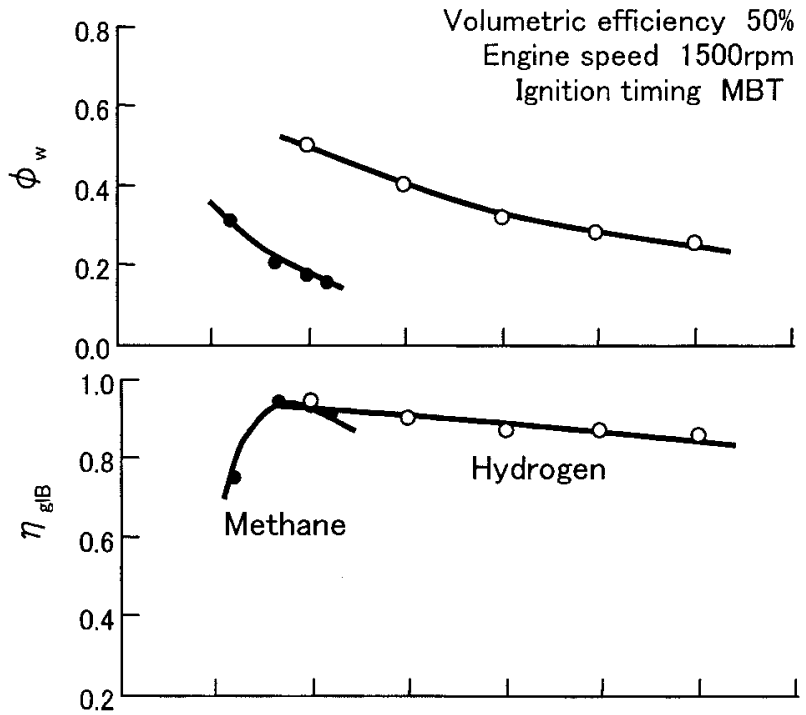

gen combustion, the exhaust temperature is lower for hydrogen combustion due to the higher cooling loss.

The exhaust heat ratio $\phi_{\text {ex }}$ was obtained by analysing the indicator diagram. The exhaust heat $Q_{e x}$ is in terms of the cumulative real heat release $Q_{B}$, the cumulative cooling loss $Q_{C}$ and the indicated work $W_{\mathrm{i}}$ in a cycle as follows:

$$
Q_{\mathrm{ex}}=Q_{\mathrm{B}}-Q_{\mathrm{C}}-W_{\mathrm{i}}
$$

Here, the cumulative real heat release $Q_{\mathrm{B}}$ and the cumulative cooling loss $Q_{C}$ describe the cumulative apparent heat release $Q$ as shown in equation (5):

$$
Q_{\mathrm{ex}}=Q-W_{\mathrm{i}}
$$

The indicated work $W_{\mathrm{i}}$ is expressed by

$$
W_{\mathrm{i}}=\eta_{\mathrm{th}} \eta_{\mathrm{glh}} Q
$$

The exhaust heat $Q_{\text {ex }}$ is described in the following form:

$$
Q_{\mathrm{ex}}=\left(1-\eta_{\mathrm{th}} \eta_{\mathrm{glh}}\right) \eta_{\mathrm{u}}\left(1-\phi_{\mathrm{w}}\right) Q_{\text {fuel }}
$$

The exhaust heat ratio $\phi_{\text {ex }}$ was defined as the ratio of exhaust heat $Q_{\text {ex }}$ to the heat of the fuel supplied per cycle $Q_{\text {fuel }}$ :

$$
\begin{aligned}
\phi_{\mathrm{ex}} & =Q_{\mathrm{ex}} / Q_{\text {fuel }} \\
& =\left(1-\eta_{\mathrm{th}} \eta_{\mathrm{glh}}\right) \eta_{\mathrm{u}}\left(1-\phi_{\mathrm{w}}\right)
\end{aligned}
$$

Here, it is known that the combustion efficiency $\eta_{\mathrm{u}}$ in stoichiometric homogeneous SI combustion hardly changes with the variation of ignition timing. Accordingly, the exhaust heat ratio $\phi_{\mathrm{ex}}$, in this case, mocouple installed in the exhaust manifold. In spite of the lower thermal efficiency in the case of hydro-

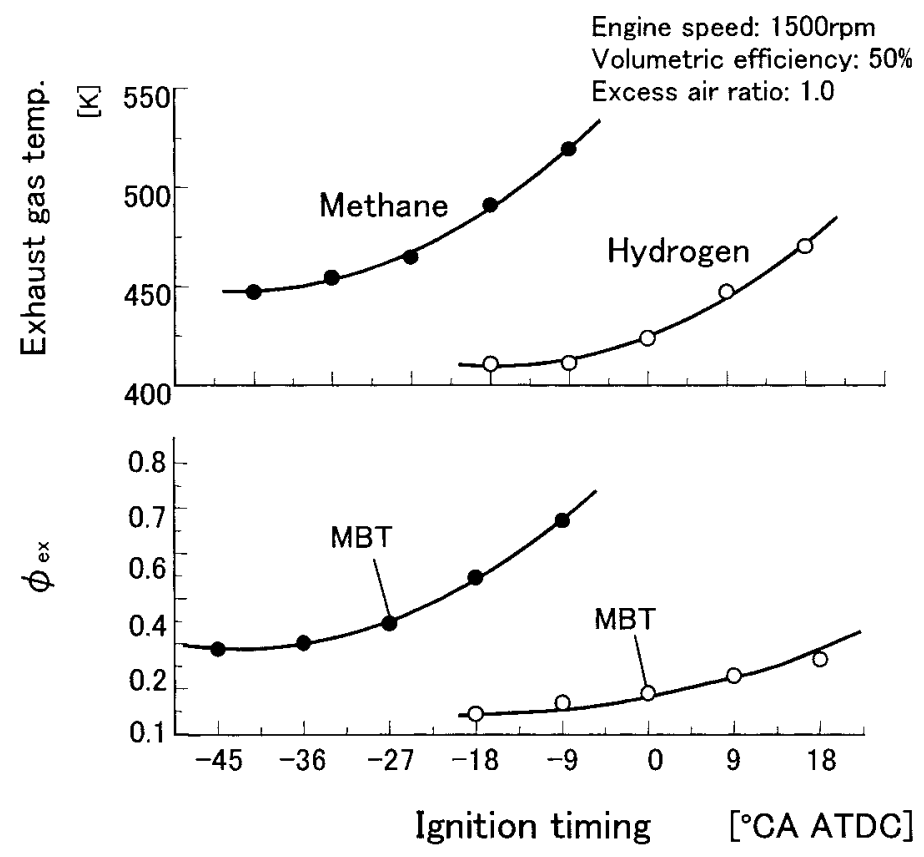

Fig. 12 Influence of ignition timing on exhaust heat characteristics. 
is mainly dominated by the degree of constant volume $\eta_{\text {glh }}$ and the cooling loss ratio $\phi_{\mathrm{w}}$.

The variation of exhaust heat ratio $\phi_{\mathrm{ex}}$ with ignition timing is similar to that of the exhaust gas temperature. For both fuels, the exhaust heat ratio $\phi_{\text {ex }}$ tends to increase with retardation of ignition timing and hydrogen combustion has a lower exhaust heat ratio $\phi_{\text {ex }}$ than methane combustion. This is due to a higher degree of constant volume $\eta_{\text {glh }}$ and cooling loss ratio $\phi_{\mathrm{w}}$ for the hydrogen combustion.

\section{Conclusion}

The cooling loss from the burning gas to the cylinder walls in a homogeneous charge SI engine was quantitatively evaluated by analysing the cylinder pressure diagram and the exhaust gas composition. The degree of constant volume burning and the degree of constant volume cooling were also obtained by fitting the Wiebe function to the rate of heat release calculated using the cylinder pressure diagram. These two methods were applied to the analysis of combustion and cooling processes of an SI gas engine fuelled with hydrogen or methane. Comparisons regarding the combustion and the cooling characteristics between hydrogen and methane combustion were made by varying the excess air ratio and ignition timing.

The results derived from the analysis are:

1. The cooling loss ratio, the ratio of the cooling loss to the real heat release, tends to decrease with the retardation of ignition timing for both hydrogen and methane combustion. This trend was confirmed by taking instantaneous heat flux measurements at a representative location in the cylinder head.

2. The cooling loss ratio in the case of hydrogen combustion is higher than that of methane combustion. This could be attributed to the thinner quenching distance and the faster burning velocity for the hydrogen combustion.

3. The degree of constant volume cooling decreases with the retardation of ignition timing and the increase in the excess air ratio for both fuels.

4. The degree of constant volume cooling in the case of hydrogen combustion is higher than that of methane combustion.

5. Both the higher cooling loss ratio and the higher degree of constant volume cooling make the thermal efficiency of hydrogen combustion lower than that of methane combustion in throttled con- ditions. Therefore, the reduction of the cooling loss ratio is essential to improve thermal efficiency of hydrogen-fuelled engines.

6. Hydrogen combustion has less exhaust heat as compared with methane combustion because of the higher degree of constant volume and the higher cooling loss ratio.

\section{Notation}

\begin{tabular}{|c|c|}
\hline$A, m$ & constants for the Wiebe function \\
\hline$D$ & cylinder bore $(\mathrm{m})$ \\
\hline$P$ & in-cylinder pressure $(\mathrm{Pa})$ \\
\hline$P_{\mathrm{m}}$ & motoring pressure $(\mathrm{Pa})$ \\
\hline$P_{\mathrm{r}}$ & $\begin{array}{l}\text { in-cylinder pressure at the } \\
\text { reference state }(\mathrm{Pa})\end{array}$ \\
\hline$Q, \mathrm{~d} Q / \mathrm{d} \theta$ & $\begin{array}{l}\text { cumulative apparent heat release } \\
(\mathrm{J}) \text {, apparent rate of heat release } \\
\left(\mathrm{J} /{ }^{\circ} \mathrm{CA}\right)\end{array}$ \\
\hline$Q_{\mathrm{B}}, \mathrm{d} Q_{\mathrm{B}} / \mathrm{d} \theta$ & $\begin{array}{l}\text { cumulative real heat release }(\mathrm{J}) \text {, } \\
\text { real rate of heat release }\left(\mathrm{J} /{ }^{\circ} \mathrm{CA}\right)\end{array}$ \\
\hline$Q_{\mathrm{C}}, \mathrm{d} Q_{\mathrm{c}} / \mathrm{d} \theta$ & $\begin{array}{l}\text { cumulative cooling loss }(\mathrm{J}) \text {, rate of } \\
\text { cooling }\left(\mathrm{J} /{ }^{\circ} \mathrm{CA}\right)\end{array}$ \\
\hline$Q_{\mathrm{ex}}$ & exhaust heat $(\mathrm{J})$ \\
\hline$Q_{\text {fuel }}$ & heat of fuel supplied per cycle $(J)$ \\
\hline$Q_{\mathrm{w}}$ & $\begin{array}{l}\text { cumulative cooling loss calculated } \\
\text { with Woschni's equation }(\mathrm{J})\end{array}$ \\
\hline$S_{\mathrm{p}}$ & mean piston speed $(\mathrm{m} / \mathrm{s})$ \\
\hline$T_{\mathrm{g}}$ & in-cylinder mean gas temperature $(\mathrm{K})$ \\
\hline$T_{\mathrm{r}}$ & $\begin{array}{l}\text { in-cylinder mean gas temperature } \\
\text { at the reference state }(K)\end{array}$ \\
\hline$V$ & in-cylinder volume $\left(\mathrm{m}^{3}\right)$ \\
\hline$V_{\mathrm{c}}$ & clearance volume $\left(\mathrm{m}^{3}\right)$ \\
\hline$V_{\mathrm{h}}$ & stroke volume $\left(\mathrm{m}^{3}\right)$ \\
\hline$V_{\mathrm{r}}$ & $\begin{array}{l}\text { in-cylinder volume at the } \\
\text { reference state }\left(\mathrm{m}^{3}\right)\end{array}$ \\
\hline$x$ & mass burnt fraction \\
\hline$\alpha$ & heat transfer coefficient $\left(\mathrm{W} / \mathrm{m}^{2} \mathrm{~K}\right)$ \\
\hline$\gamma$ & ratio of specific heats \\
\hline$\eta_{\mathrm{e}}$ & brake thermal efficiency \\
\hline$\eta_{\mathrm{glB}}$ & $\begin{array}{l}\text { degree of constant volume } \\
\text { burning }\end{array}$ \\
\hline$\eta_{\mathrm{glC}}$ & degree of constant volume cooling \\
\hline$\eta_{\mathrm{glh}}$ & degree of constant volume \\
\hline$\eta_{\mathrm{i}}$ & indicated thermal efficiency \\
\hline$\eta_{\text {th }}$ & $\begin{array}{l}\text { theoretical thermal efficiency of } \\
\text { the Otto cycle }\end{array}$ \\
\hline$\eta_{\mathrm{u}}$ & combustion efficiency \\
\hline$\eta_{\mathrm{v}}$ & volumetric efficiency (\%) \\
\hline$\theta$ & crank angle $\left({ }^{\circ} \mathrm{CA}\right)$ \\
\hline$\theta_{\mathrm{f}}$ & $\begin{array}{l}\text { beginning of combustion in the } \\
\left.\text { Wiebe function ( }{ }^{\circ} \mathrm{CA}\right)\end{array}$ \\
\hline
\end{tabular}

constants for the Wiebe function inder bore $(\mathrm{m})$ in-cylinder pressure at the (J), apparent rate of heat release real rate of heat release $\left(\mathrm{J} /{ }^{\circ} \mathrm{CA}\right)$ ate of heat of fuel supplied per cycle (J) cumulative cooling loss calculated with Woschni's equation (J) mean piston speed $(\mathrm{m} / \mathrm{s})$ in-cylinder mean gas temperature $(\mathrm{K})$ rature -cylinder volume $\left(\mathrm{m}^{3}\right)$ learance volume $\left(\mathrm{m}^{3}\right)$ troke volume $\left(\mathrm{m}^{3}\right)$ in-cylinder volume at the reference state $\left(\mathrm{m}^{3}\right)$ mass burnt fraction transfer coefficier olume burning degree of constant volume cooling degree of constant volume indicated thermal efficiency theoretical thermal efficiency of the Otto cycle volumetric efficiency (\%) beginning of combustion in the Wiebe function $\left({ }^{\circ} \mathrm{CA}\right)$ 


$\begin{array}{ll}\theta_{\mathrm{z}} & \text { combustion period in the Wiebe } \\ \lambda & \text { function }\left({ }^{\circ} \mathrm{CA}\right) \\ \phi_{\mathrm{ex}} & \text { excess air ratio } \\ \phi_{\mathrm{w}} & \text { exhaust heat ratio } \\ & \text { cooling loss ratio }\end{array}$

\section{Acknowledgement}

The authors wish to express their thanks to Professor Kamimoto of Tokai University for reading the manuscript and making a number of helpful suggestions.

\section{References}

1 Ricardo, H. F. Further note on fuel research. Proc. Instn Automot. Engng, 1924, 18, 327-341.

2 King, R. O., Wallace, W. A. and Mahapatra, B. The hydrogen engine and the nuclear theory. Can. J. Res. 1948, 264.

3 Billings, R. E., Woolley, R. L. and Henriksen, D. L. Water injection in hydrogen powered IC engine. In Proceedings of the 1st World Hydrogen Energy Conference, Vol. 3, 1976, p. 27.

4 Lewis, B. and von Elbe, G. Combustion, Flames and Explosions of Gases, 1961, pp. 331-335 (Academic Press).

5 List, H. Thermodynamik der Verbrennungskraftmaschinen, 1939 , p. 71 (Springer-Verlag, Berlin).

6 Heywood, J. B. Internal Combustion Engine Fundamentals, 1988, p. 82 (McGraw-Hill).

7 Sitkei, G. Kraftstoffaufbereitung und Verbrennung bei Dieselmotoren, 1964, pp. 156-159 (Springer-Verlag, Berlin).

8 Ferguson, C. R. Internal Combustion Engines Applied Thermosciences, 1986, p. 386 (John Wiley).

9 Ramos, J. I. Internal Combustion Engine Modeling, 1989, pp. 116-120 (Hemisphere, New York).

10 Woschni, G. Universally applicable equation for instantaneous heat transfer coefficient in the internal combustion engine. SAE Paper 670931, 1967. 